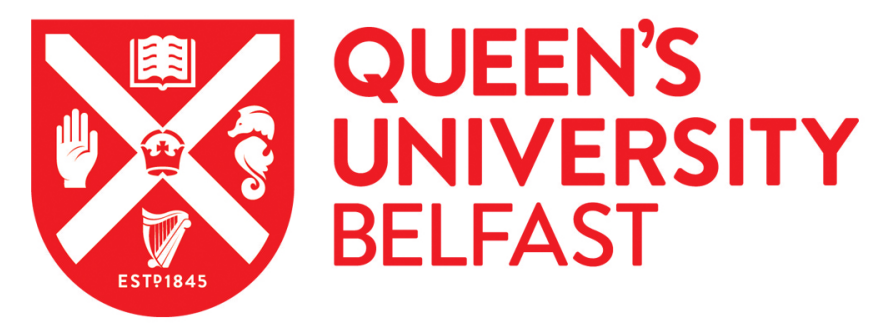

\title{
Development and Application of Medication Appropriateness Indicators for Persons with Advanced Dementia: A Feasibility Study
}

Parsons, C., McCann, L., Passmore, P., \& Hughes, C. (2015). Development and Application of Medication Appropriateness Indicators for Persons with Advanced Dementia: A Feasibility Study. Drugs \& Aging, 32(1), 6777. https://doi.org/10.1007/s40266-014-0226-9

Published in:

Drugs \& Aging

Document Version:

Peer reviewed version

Queen's University Belfast - Research Portal:

Link to publication record in Queen's University Belfast Research Portal

Publisher rights

CSpringer International Publishing Switzerland 2014

The final publication is available at Springer via http://dx.doi.org/10.1007/s40266-014-0226-9

\section{General rights}

Copyright for the publications made accessible via the Queen's University Belfast Research Portal is retained by the author(s) and / or other copyright owners and it is a condition of accessing these publications that users recognise and abide by the legal requirements associated with these rights.

Take down policy

The Research Portal is Queen's institutional repository that provides access to Queen's research output. Every effort has been made to ensure that content in the Research Portal does not infringe any person's rights, or applicable UK laws. If you discover content in the Research Portal that you believe breaches copyright or violates any law, please contact openaccess@qub.ac.uk. 


\section{Development and application of medication appropriateness indicators for persons with advanced dementia - a feasibility study}

Carole Parsons $^{1}$, Laura McCann ${ }^{2}$, Peter Passmore ${ }^{3}$, Carmel Hughes ${ }^{1}$

${ }^{1}$ School of Pharmacy, Queen's University Belfast, 97 Lisburn Road, Belfast, BT9 7BL, Northern Ireland, UK

${ }^{2}$ Northern Ireland Centre for Pharmacy Learning and Development, Queen's University

Belfast, Riddel Hall, 185 Stranmillis Road, Belfast, BT9 5EE, Northern Ireland, UK

${ }^{3}$ Centre for Public Health, School of Medicine, Dentistry and Biomedical Sciences, Queen's University Belfast, Royal Victoria Hospital, Belfast, BT12 6BA, Northern Ireland, UK

Running title: Medication appropriateness in persons with advanced dementia

Correspondence: Dr Carole Parsons, School of Pharmacy, Queen's University Belfast, 97 Lisburn Road, Belfast, BT9 7BL, Northern Ireland.

Mailing address: School of Pharmacy, Queen’s University Belfast, 97 Lisburn Road, Belfast, BT9 7BL, Northern Ireland

Phone: +44(0)2890972304 Fax: +44(0)2890247794 E-mail: c.parsons@qub.ac.uk (email address may be published) 


\section{Acknowledgments}

Funding sources: The authors had financial support from the Alzheimer's Society and the Bupa Foundation for the submitted work (Grant reference 137). The authors' work was independent of the funders; the Alzheimer's Society and the Bupa Foundation did not contribute to the study design; the collection, analysis, or interpretation of data; the writing of the report; or the decision to submit the article for publication.

Conflicts of interest: Peter Passmore has received funding (educational grants) from Napp and Grünenthal and has spoken at and/or chaired meetings for these companies. Napp and Grünenthal had no role in the development, analysis and reporting of this study. The other authors have no conflicts to report.

Author contributions: Carole Parsons, Carmel Hughes, Peter Passmore: study design, analysis, interpretation of data and preparation of the manuscript. Laura McCann: acquisition of data, analysis, interpretation of data and preparation of the manuscript.

Other contributions: The authors wish to thank Dr Chris Cardwell (School of Medicine, Dentistry and Biomedical Sciences, Queen's University Belfast, Northern Ireland, UK), and Dr Holly Holmes (The University of Texas MD Anderson Cancer Center, Houston, Texas, USA) for their advice regarding study design. The authors would also like to thank the physicians who participated in the Delphi consensus panel survey, and the residents, their relatives and care home staff who participated in the feasibility study. 


\begin{abstract}
Background: No studies have been conducted in the United Kingdom (UK) context to date which categorise medications in terms of appropriateness for patients with advanced dementia, or which examine medication use in these vulnerable patients.
\end{abstract}

Objectives: To categorise the appropriateness of a comprehensive list of medications and medication classes for use in patients with advanced dementia; to examine the feasibility of conducting a longitudinal prospective cohort study to collect clinical and medication use data; and to determine the appropriateness of prescribing for nursing home residents with advanced dementia in Northern Ireland (NI), using the categories developed.

Methods: Three-round Delphi consensus panel survey of expert clinicians, to categorise the appropriateness of medications for patients with advanced dementia (defined as having Functional Assessment Staging [FAST] scores ranging from 6E to 7F). This was followed by a longitudinal prospective cohort feasibility study which was conducted in three nursing homes in NI. Clinical and medication use for participating residents with advanced dementia (FAST scores ranging from $6 \mathrm{E}$ to $7 \mathrm{~F}$ ) were collected and a short test of dementia severity administered. These data were collected at baseline and every three months for up to nine months or until death. For those residents who died during the study period, data were also collected within 14 days of death. The appropriateness ratings from the consensus panel survey were retrospectively applied to residents' medication data at each data collection timepoint to determine the appropriateness of medications prescribed for these residents.

Results: Consensus was achieved for 87 (90\%) of the 97 medications and medication classes included in the survey. Fifteen residents were recruited to participate in the longitudinal prospective cohort feasibility study, four of whom died during the data collection period. Mean 
numbers of medications prescribed per resident were 16.2 at baseline, 19.6 at three months, 17.4 at six months and 16.1 at nine months respectively. Fourteen residents at baseline were taking at least one medication considered by the consensus panel to be never appropriate, and approximately $25 \%$ of medications prescribed were considered to be never appropriate. Postdeath data collection indicated a decrease in the proportion of never appropriate medications and an increase in the proportion of always appropriate medications for those residents who died.

Conclusions: This study is the first to develop and apply medication appropriateness indicators for patients with advanced dementia in the UK setting. The Delphi consensus panel survey of expert clinicians was a suitable method of developing such indicators. It is feasible to collect information on quality of life, functional performance, physical comfort, neuropsychiatric symptoms and cognitive function for this subpopulation of nursing home residents with advanced dementia.

\section{Key Points}

- This study is the first to develop medication appropriateness indicators forpatients with advanced dementia in the United Kingdom (UK) setting

- It categorises a comprehensive list of medications and medication classes as never appropriate, rarely appropriate, sometimes appropriate or always appropriate for use in patients with advanced dementia

- Fourteen of the fifteen participating residents at baseline were taking at least one never appropriate medication, and approximately $25 \%$ of medications prescribed were never appropriate. Post-death data collection indicated a decrease in the proportion of never appropriate medications and an increase in the proportion of always appropriate medications as death approached. 
- This study demonstrates the feasibility of conducting a longitudinal prospective cohort study to collect clinical and medication use data, and to determine the appropriateness of prescribing for nursing home residents with advanced dementia in Northern Ireland (NI)

\section{Introduction}

Advanced dementia is characterised by profound cognitive and functional impairment, inability to ambulate independently, urinary and faecal incontinence, and minimal verbal communication $[1,2]$. Studies of medication use in populations with a reduced life expectancy, albeit not specific to patients with advanced dementia, have highlighted the prevalence of suboptimal and inappropriate medication use [3-8]. Persons with advanced dementia are more likely to be subject to polypharmacy than healthier persons with a longer life expectancy and are at increased risk of inappropriate prescribing and adverse outcomes as a result of medication therapy $[6,9-11]$. They are at greater risk of receiving overly aggressive care [12], and often have a prolonged terminal phase in advanced disease [13]. They may experience a high level of symptoms including shortness of breath, constipation, febrile episodes, agitation and eating problems [1, 13-19].

Medication use among patients with advanced dementia has been inadequately characterised to date. Most of the limited number of studies conducted in this area [15, 20-23] have utilised prospective longitudinal cohort designs to describe medication use over time either as the key objective $[15,20,21]$ or as part of a much wider study of end-of-life care of persons with advanced dementia [24], although larger cross-sectional studies of medication use which are less geographically limited in their study populations are starting to appear in the

published literature [2]. Appropriateness of prescribing was considered in a number of these 
studies which focused on nursing home residents with advanced dementia nearing the end of life in the USA $[2,21,22]$, in Italian patients with advanced dementia residing in long-term care institutions or at home [23], and patients admitted to an acute geriatric unit in Spain [25]. The majority of these studies employed the classification system developed by Holmes et al., [21] which categorised medications as never appropriate, rarely appropriate, sometimes appropriate or always appropriate for persons with advanced dementia in whom palliation of symptoms was the primary goal of therapy [2, 21-23].

To the knowledge of the authors, no studies have been conducted in the United Kingdom (UK) context to date which categorise medication appropriateness for patients with advanced dementia who are nearing the end of life or which examine medication use by these vulnerable patients. The aims of this study were to develop such a classification system, to examine the feasibility of conducting a longitudinal prospective cohort study to collect clinical and medication use data, and to determine the appropriateness of prescribing for nursing home residents with advanced dementia in Northern Ireland (NI) using the system developed.

\section{Methods}

\subsection{Delphi Consensus Panel}

Physicians who were members of the Clinical Management Group of the Northern Ireland Clinical Research Network for Dementia $(n=9)$ were invited to participate in a consensus panel to rate medication appropriateness in persons with advanced dementia in whom palliation of symptoms is the primary goal of therapy. This panel is representative of specialists who provide care to patients with advanced dementia in the UK and includes geriatricians $(n=4)$ [one of whom specialises in pharmacology and therapeutics], old age psychiatrists $(n=4)$, and one neurologist. 
A postal questionnaire was administered in a three-round Delphi process. In the first round (July 2011), participants were mailed a selection of literature regarding medication use in palliative care, a conceptual model regarding prescribing for patients late in life (to provide background information and to assist in the classification of medications into appropriateness categories $[20,21,26,27])$, and a questionnaire. The questionnaire collected demographic data and data regarding clinical practice pertaining to each participant, including: age; sex; details of current job title; area of practice; and percentage of typical working week spent in clinical practice. Participants were also asked to indicate their professional and personal experience in caring for persons with dementia nearing the end of life, using a scale from 1 (representing limited experience) to 10 (extremely experienced). Participants were asked if they had received training in palliative care, and if so, whether this was delivered as part of a formal palliative care training programme. Participants were then asked to place the appropriateness of 85 medications and medication classes, into one of four categories: never appropriate, rarely appropriate, sometimes appropriate or always appropriate for use in patients with advanced dementia. Medications were selected based on the classification system used in the British National Formulary (BNF) [28], ensuring a rational organisation of medications into therapeutic classes. Participants were also given the opportunity to add any medications not included that they thought were important. Physicians were instructed to assume that the patients for whom they were assessing medication appropriateness had Functional Assessment Staging (FAST) scores ranging between 6E and 7F [29, 30]. This corresponds to patients who need assistance with bathing, dressing and toileting, and who have urinary and faecal incontinence (FAST 6E); who have minimal verbal ability (FAST 7A and 7B); who are unable to ambulate (FAST 7C); sit up (FAST 7D); or smile (FAST 7E); or who cannot hold their head up (FAST 7F). While patients with FAST scores of 6E may be considered to have moderately-severe dementia, categorisation of the appropriateness of medications by the 
Delphi consenus panel included these patients to enable comparisons to be drawn with the system developed by Holmes et al. [21], which included patients with FAST scores of 6E and above.

In the second and third rounds of the survey (January and July 2012 respectively), participants were mailed further copies of the questionnaire which had been modified to remind them of their responses in the previous round and which contained an anonymous summary of all responses including the most common response regarding appropriateness of each medication or medication class. Consistent with other Delphi methods and other studies $[21,31]$, consensus for a medication or medication class was defined according to agreement on categorisation by at least $55 \%$ of the respondents (corresponding to 5 of the 9 physicians on the panel). This provided the opportunity to revise the medication appropriateness categorisations on the basis of the group's responses and aimed to increase consensus within each round. Any medication(s) for which consensus was achieved by $100 \%$ of the respondents in a previous round was omitted from the questionnaire in the subsequent round. Each respondent was reimbursed $£ 250$ for their participation on completion of the three rounds of the survey. All responses to the final round were returned by January 2013.

\subsection{Longitudinal prospective cohort study}

\subsubsection{Nursing home recruitment}

The feasibility study was conducted in three nursing homes in NI. Nursing homes with more than 30 resident beds (the average number of beds in a nursing home in NI) were eligible to participate; this included homes for general nursing category residents and those which provided specialised dementia care $(\mathrm{n}=181)$. Based on the authors' knowledge of, and previous collaborative research programmes involving nursing homes in NI, a convenience sample of three homes was selected. Written consent was obtained from the managers of these 
participating nursing homes. It was estimated that around one-third of residents would have advanced dementia ( $n=10$ per home) and of these, $50 \%$ would participate ( $n=5$ per home), yielding a total sample size of 15 residents from three nursing homes, which was considered sufficient for this feasibility study.

\subsubsection{Resident recruitment}

The recruitment process for eligible residents involved a number of stages. Nursing home managers identified residents with dementia and the members of nursing staff who provided most care to each of these residents on a regular basis (the residents' named nurse). Eligibility criteria for residents were as follows: (1) 60 years of age or older, (2) diagnosis of dementia, (3) FAST score between $6 \mathrm{E}$ and 7F, (4) resident in the nursing home for at least 30 days, (5) not participating in any other research or studies. Eligibility criteria for named nurses were that the nurse was (1) regularly assigned to care for this resident and (2) not participating in any other research or studies. As residents with advanced dementia lack decisional capacity, written informed assent from their next-of-kin or legal guardian was obtained to screen the resident for eligibility to participate and to examine medical records held by residents' primary care physicians (general practitioners [GPs]) to confirm a diagnosis of dementia. Written informed consent was also obtained from residents' named nurses to complete functional assessment staging of the resident using the FAST scale [29]. Upon confirmation of eligibility to participate, written assent was obtained from the residents' next-of-kin or legal guardians and written informed consent obtained from residents' named nurses for participation in the study. Where more than five residents were eligible for screening at each of the three homes and subsequently determined to be eligible, five were randomly selected to take part in the study. 


\subsubsection{Data Collection and Analysis}

The following data were collected at baseline: nursing home characteristics, including: ownership (private, statutory, voluntary, single home ownership, part of a chain of homes); number of nurses on staff; number of beds; type of care home (general nursing home, home offering specialised dementia care); location (rural or urban); number of general practices and GPs providing care to the nursing home; and extent of involvement of old age psychiatry in the home. Other data were collected at baseline and every three months for up to nine months or until deathbetween October 2011 and September 2012, as detailed in Table 1.

As the Delphi consensus panel survey was completed in January 2013, the appropriateness ratings from the consensus panel recommendations were applied retrospectively to each resident's medication data at each data collection timepoint to determine which of the residents' medications were never appropriate, rarely appropriate, sometimes appropriate or always appropriate. The feasibility of using the proposed approach to collect clinical data and data pertaining to medication use was also determined. Statistical analysis was descriptive.

\subsection{Ethical and Governance Approvals}

Ethical approval was obtained from the Office for Research Ethics Committees Northern Ireland (ORECNI). Research governance approval was obtained from the organisations employing the physicians who participated in the consensus panel survey.

\section{Results}

\subsection{Delphi Consensus Panel survey}

All nine physicians ( 7 males and 2 females, mean age 45 years) from the Clinical Management Group of the Northern Ireland Clinical Research Network for Dementia agreed to participate in the consensus panel and completed the three rounds of the survey. Respondents spent an 
average of $86.6 \%$ of their working week in clinical practice and the majority $(n=7)$ had received training in the delivery of palliative care; however this was not always delivered as part of a formal training programme. All physicians, apart from one, rated themselves as highly experienced as a professional caring for persons nearing the end of life, with scores ranging from 4-10 (mean score for all participants $=8.33$ ). Two physicians rated themselves as highly experienced in their personal lives in caring for persons with dementia nearing the end of life, with scores ranging from $1-10$ (mean score for all participants $=6.43)$.

Increasing consensus regarding the appropriateness of medications and medication classes was achieved with each survey round. Twelve medications or medication classes not included in rounds 1 and 2 of the survey were considered important by the physicians and subsequently added. After round 3, consensus had been achieved for 87 (90\%) of the 97 medications and medication classes included in the survey. The complete list of medications and their appropriateness ratings as determined by the consensus panel are detailed in Table 2 .

\subsection{Longitudinal prospective cohort study}

\subsubsection{Nursing home characteristics}

The three participating homes were privately owned with 40,56 , and 49 beds respectively (average number of beds $=48)$. Only one home $(\mathrm{NH} 3)$ had an Elderly Mental Infirm (EMI) unit which provided specialist dementia care $(n=9$ beds). There was involvement of an old age psychiatry team at all three homes (psychiatrists assessed and reviewed residents with dementia when required) and on average, GPs from seven general practices provided care at each home (Table 3).

\subsubsection{Resident characteristics}


Three of the thirty-three eligible residents died before screening could take place and a number of next-of-kin did not return signed assent forms to allow screening to take place. Nine residents per home were screened for eligibility to participate and five residents were randomly selected.

Of the 15 residents recruited (average age 86 years), 10 were female and five were male. Prior to nursing home admission, eight residents resided in their own home, two in a residential home, one in sheltered accommodation and one in another nursing home. The types of dementia documented (primarily from GP records) varied: six residents were diagnosed as having Alzheimer's disease, four were coded as having vascular dementia and two had multiple infarct dementia. Senile dementia was coded for two residents and one resident was diagnosed as having unspecified dementia. Mean duration of dementia was just under six years (71.4 months). Unadjusted Charlson co-morbidity scores ranged from 1 to 4, and age-adjusted scores ranged from 4 to 8 . Four residents died during the study period (three before the three-month data collection point and one before the six-month data collection point); documented causes of death were bronchial pneumonia $(n=3)$, and a perforated bowel $(n=1)$. One resident was transferred to another nursing home.

FAST scores ranged from 6E (faecal incontinence) to 7D (could not sit up) at the four data collection points (Table 4). NPI-NH scores are also detailed at each data collection point in Table 4; the presence of behavioural disturbances varied greatly across the 15 residents recruited to the study with each resident experiencing at least one of the 10 behavioural disturbances occurring in dementia throughout the duration of the study. Caregiver distress scores, scores for cognitive function (using the short version of the Severe Impairment Battery [SIB-S]), quality of life (using the Quality of Life in late stage Dementia [QUALID] scale) and 
symptom management at the end of life (using the Symptom Management at the End of Life in Dementia [SM-EOLD] scale) are outlined in Table 4.

\subsubsection{Prevalence and Appropriateness of Medication Use}

Mean numbers of medications prescribed per resident were 16.2 at baseline, 19.6 at three months, 17.4 at six months and 16.1 at nine months respectively. This included regular and when-required medications, topical and ophthalmic preparations and nutritional supplements.

The numbers of medications prescribed in each appropriateness category are summarised in Table 5. At baseline, approximately one-quarter of the medications prescribed for residents were considered by the consensus panel to be never appropriate. Fourteen of the 15 participating residents were prescribed at least one of these medications. Use of medications classified as never appropriate by the consensus panel did not change significantly as the study progressed. Similarly the percentage of medications classified as always appropriate remained stable over the period of data collection, ranging from $16.9 \%$ at baseline to $15.1 \%, 18.1 \%$ and $18.4 \%$ at three, six and nine months respectively. The post-death data collection indicated that there was a decrease in the proportion of never appropriate medications (12.0\%) and an increase in the proportion of always appropriate medications (28.0\%) for those residents who died during the study period.

\section{Discussion}

This study utilised Delphi methodology to develop a classification system for the appropriateness of prescribing for patients with advanced dementia nearing the end of life. This method was selected as it involves sequential anonymous postal questionnaires 
interspersed by controlled feedback, and seeks to gain the most reliable consensus of opinion of a group of experts [39]. Furthermore, the avoidance of face-to-face interaction between group members prevents bias as each panel member is able to express their own opinions away from peer pressure [40].

Categorisation of medication appropriateness showed similarities to the classification system developed by Holmes et al. [21], in which consensus was achieved for 69 (85\%) of the 81 included medications and medication classes. In the present study, consensus was achieved for a similar proportion of medications and medication classes (90\%) despite the slightly higher number of medications and medication classes included $(n=97)$. There were, however, some notable differences; in the classification system developed by Holmes et al. [21], no consensus was achieved for aspirin, iron, vitamins, mineral supplements or finasteride, while in the present study, these medications were classified as never appropriate. Holmes et al. [21] classified acetylcholinesterase inhibitors and N-methyl-D-aspartate receptor antagonists (memantine) as never appropriate; the consensus among the physicians in the present study was that these agents were rarely appropriate and sometimes appropriate respectively. Furthermore, there were some medications, namely expectorants and tricyclic antidepressants, for which classifications of appropriateness varied widely. This variation may in part be explained by cross-national or cultural differences in prescribing in US and UK jurisdictions but may also reflect the complexity and variability in decision-making regarding medication use at the end of life for patients with advanced dementia and the lack of evidence-based guidance available to guide clinical practice $[8,27,41]$.

FAST scores for participating residents ranged from 6E to 7D during the data collection period. Residents with FAST scores of $6 \mathrm{E}(\mathrm{n}=4)$ were in the less advanced stages of the disease, had higher scores on the SIB-S and better quality of life than residents with FAST scores of 7A and above. In the Delphi consensus process, physicians categorised the appropriateness of 
medications for use in patients with advanced dementia with FAST scores ranging between $6 \mathrm{E}$ and 7F. A recent study by Toscani et al. [23] examined the appropriateness of prescribing for Italian patients with advanced dementia residing in long-term care institutions and at home using the classification system developed by Holmes et al. [21]. In this study, patients with a FAST score of $\geq 7$ were enrolled, but the authors reported data on patients with FAST scores of $\geq 7 \mathrm{C}$ as they argued that these patients had advanced dementia for which palliative care was clearly appropriate. However, the classification system developed by Holmes et al. [21] determined medication appropriateness in the context of providing care to patients with moderate to severe dementia approximating FAST stages 6E, 7A, 7B and 7C, and the authors recognised that the criteria on appropriateness of some medications may require reconsideration in the view of the advanced stage of dementia among the participants [23]. In terms of the eligibility criteria for a subsequent extension of the present feasibility study to a larger study, inclusion of patients with FAST scores of 7A and above should be considered, although this may require the validation of the Delphi consensus panel recommendations for such patients and may have an impact on the number of eligible residents from which to recruit. Other researchers have utilised a Global Deterioration Scale (GDS) of 7 (characterised by profound memory deficits, minimal or no verbal communication, urinary and faecal incontinence and inability to walk) to define advanced dementia [1, 24]. A recent study by Molist Brunet et al. [25] used a combination of three measures to identify patients with advanced dementia: an inability to complete activities of daily living (defined by a Barthel index $\leq 30 / 100$ ), incontinence, and difficulty recognising family members [defined as a GDS of $\geq 6$ in the case of Alzheimer type dementia]), while Tjia et al. [2] used a Cognitive Performance Score (CPS) of 5 or 6 and the Minimum Data Set diagnosis of dementia [2]. There is a recognition in the literature that the criteria used to define advanced dementia vary between studies, and that a consistent definition that can be applied both in clinical practice and in 
research, and in a standardised manner, is required [42]. This should be considered in the design of any future study in nursing homes in the NI or UK contexts.

It is well-acknowledged that dementia is associated with chronic comorbidities [23, 42, 43], and the findings from the present study, in which age-adjusted Charlson co-morbidity scores ranged from 4 to 8 , corroborate this. Although numbers recruited to this feasibility study were small, it has highlighted the number of patients with lack of specificity in their diagnosis of dementia; this is recognised to be an issue particularly because treatment and prognosis may differ substantially based on the differential diagnosis [44].

The mean numbers of medications prescribed per resident at each data collection point were similar to the mean number of medications prescribed per resident in the Care of Nursing Home Residents with Advanced Dementia [CareAD] study [20], in which patients were prescribed a mean of 14.6 medications. Other studies have reported lower numbers of medications per resident ranging from a median of 4 medications [23] to means of 5.9, 6.5 and 7.3 medications per person [21, 22, 25]. However, this may in part be explained by the differences in medications included in and excluded from the analysis in each study.

Examination of the appropriateness of prescribing for residents using the Delphi consensus panel ratings revealed that 14 of the 15 residents at baseline were taking at least one medication considered by the consensus panel to be never appropriate, and that a significant proportion of medications (approximately one-quarter) prescribed were considered to be never appropriate. These figures are higher than those reported in previous studies [2, 21-23], but do provide further evidence to support the conclusions of Tjia et al. in their recent publication [2] that "most nursing home residents with advanced dementia receive medications of questionable benefit". Variations in the prevalence reported in these studies may be explained by the differences in medications included in and excluded from the analysis in each study; for 
example, in the study by Tjia et al. [22], drugs prescribed on a when-required basis, topical preparations, vitamins (with the exception of vitamin D) and antimicrobials were not included whereas in the present study, regular and when-required medications, antimicrobials, topical and ophthalmic preparations and nutritional supplements were included. Further, in the classification system developed by Holmes et al. [21] and utilised in the studies by Tjia et al. [2,22] and Toscani et al. [23], no consensus was achieved for aspirin, iron, vitamins, mineral supplements or finasteride, while in the present study these medications were classified as never appropriate.

Prescribing of medications classified as never appropriate did not change significantly as the study progressed. Similarly the percentage of medications classified as always appropriate remained stable over the period of data collection. The post-death data collection indicated that there was a decrease in the proportion of never appropriate medications and an increase in the proportion of always appropriate medications for those residents who died during the study period. This is noteworthy despite the small number of residents involved; it may suggest a move away from curative goals of therapy towards palliative management of symptoms, as has been observed in other studies [3, 20, 21, 45].

This study is the first to develop indicators for, and to report prevalence of, appropriate medication use in patients with advanced dementia nearing the end of life in the UK setting. There are, however, some limitations to this study which must be acknowledged. The Delphi consensus panel took significantly longer to complete than had been originally anticipated. This may have been due in part to the length of the survey, which required classification of 97 medications/medication classes into appropriateness categories. In order to facilitate the completion of any further consensus panel survey in an expeditious manner, administration via other methods such as a face-to-face meeting or online distribution could be considered. Furthermore, a larger representative consensus panel comprising physicians from a range of 
locations, clinical specialities and settings is required to extend the generalizability and scope of these findings. Numbers recruited to this feasibility study were small, and the ability to draw generalizable conclusions is limited. Although a number of residents with FAST scores of between 7B-7E (severely demented) were unable to complete the short version of the SIB-S, use of this scale enabled assessment of cognitive function in residents who had such advanced dementia that they would have been unable to complete any other test of cognitive function. Future larger-scale studies should therefore continue to utilise the SIB-S to measure cognitive function. Previous work undertaken by Garfinkel et al., [46, 47] has reported that medication discontinuation using a geriatric-palliative approach and algorithm has favourable effects on mortality and morbidity, and lends support to further work developing and evaluating measures of medication appropriateness for older people with advanced dementia to provide an evidencebase for rationalisation of prescribing in this vulnerable patient group.

Despite these limitations, the Delphi consensus panel survey was a suitable method of gaining consensus among expert clinicians on appropriateness of medications. The study findings demonstrate the feasibility of collecting information from medical records, from researcherconducted interviews with residents' named nurses and from a researcher assessment of cognitive function using the SIB-S. This three-staged approach to data collection would therefore be suitable for use in a larger study.

\section{Conclusion}

This study is the first to develop and apply indicators for medication appropriateness for patients with advanced dementia nearing the end of life in the UK setting. It demonstrates the feasibility and suitability of utilising a Delphi consensus panel of experts to classify the appropriateness of medications for use in patients with advanced dementia. Data collection indicated that it is feasible to collect information on quality of life, functional performance, 
physical comfort, neuropsychiatric symptoms and cognitive function for nursing home residents with advanced dementia who are nearing the end of life.

\section{References}

1. Mitchell SL, Teno JM, Kiely DK, et al. The clinical course of advanced dementia. N Engl J Med 2009;361(16): 1529-38.

2. Tjia J, Briesacher BA, Peterson D, et al. Use of medications of questionable benefit in advanced dementia. JAMA Intern Med 2014 (epub ahead of print).

3. Currow DCB, Stevenson JP, Abernethy AP, et al. Prescribing in palliative care as death approaches. J Am Geriatr Soc 2007;55(4): 590-5.

4. Fahlman C, Lynn J, Finch M, et al. Potentially inappropriate medication use by Medicaid Choice beneficiaries in the last year of life. J Palliat Med 2007;10(3): 686-95.

5. Spinewine A, Schmader KE, Barber N, et al. Appropriate prescribing in elderly people: how well can it be measured and optimised? Lancet 2007;370(9582): 173-84.

6. Holmes HM. Rational prescribing for patients with a reduced life expectancy. Clin Pharmacol Ther 2009;85(1): 103-7.

7. O’Mahony D, O'Connor MN. Pharmacotherapy at the end of life. Age Ageing 2011;40:41922.

8. Cruz-Jentoft AJ, Boland B, Rexach L. Drug therapy optimization at the end of life. Drugs Aging 2012;29:511-21. 
9. Hajjar ER, Cafiero AC, Hanlon JT. Polypharmacy in elderly patients. Am J Geriatr Pharmacother 2007;5(4): 345-51.

10. Laroche ML, Charmes JP, Bouthier F, et al. Inappropriate medications in the elderly. Clin Pharmacol Ther 2008;85(1): 94-7.

11. Thorpe JM, Thorpe CT, Kennelty KA, et al. The impact of family caregivers on potentially inappropriate medication use in non-institutionalized older adults with dementia. Am J Geriatr Pharmacother 2012;10(4): 230-41.

12. Mitchell SL, Kiely DK, Hamel MB. Dying with advanced dementia in the nursing home. Arch Intern Med 2004;164(3): 321-6.

13. McCarthy M, Addington-Hall J, Altmann D. The experience of dying with dementia: a retrospective study. Int J Geriatr Psychiatry 1997;12(3):404-9.

14. Bayer A. Death with dementia-the need for better care. Age Ageing 2006;35(2): 101-2.

15. Black BS, Finucane T, Baker A, et al. Health problems and correlates of pain in nursing home residents with advanced dementia. Alzheimer Dis Assoc Disord 2006;20:283-90.

16. Shega JW, Hougham GW, Stocking CB, et al. Patients dying with dementia: experience at the end of life and impact of hospice care. J Pain Symptom Manage 2008;35:499-507.

17. Di Giulio P, Toscani F, Villani D, et al. Dying with advanced dementia in long-term care geriatric institutions. J Palliat Med 2008;11:1023-8.

18. Shega J, Tozer C. Improving the care of people with dementia at the end of life: The role of hospice and the US experience. Dementia 2009;8(3): 377-89.

19. Hendriks SA, Smalbrugge M, Hertogh CMPM, et al. Dying with dementia: symptoms, treatment, and quality of life in the last week of life. J Pain Symptom Manage 2014;47:710-20. 
20. Blass DM, Black BS, Phillips H, et al. Medication use in nursing home residents with advanced dementia. Int J Geriatr Psychiatry 2008;23(5):490-6.

21. Holmes HM, Sachs GA, Shega JW, et al. Integrating palliative medicine into the care of persons with advanced dementia: identifying appropriate medication use. J Am Geriatr Soc 2008;56(7):1306-11.

22. Tjia J, Rothman MR, Kiely DK, et al. Daily medication use in nursing home residents with advanced dementia. J Am Geriatr Soc 2010;58;880-8.

23. Toscani F, Di Giulio P, Villani D, et al. Treatments and prescriptions in advanced dementia patients residing in long-term care institutions and at home. J Palliat Med 2013;16(1);31-7.

24. Mitchell SL, Kiely DK, Jones RN, et al. Advanced dementia research in the nursing home: the CASCADE study. Alzheimer Dis Assoc Disord 2006;20:166-75.

25. Molist Brunet N, Sevilla-Sánchez D, Amblàs Novellas J, et al. Optimizing drug therapy in patients with advanced dementia: a patient-centered approach. Eur Geriatr Med 2014;5:66-71.

26. Holmes HM, Hayley DC Alexander GC, et al. Reconsidering medication appropriateness for patients late in life. Arch Intern Med 2006;166:605-9.

27. Parsons C, Hughes CM, Passmore AP, et al. Withholding, discontinuing and withdrawing medications in dementia patients at the end of life: a neglected problem in the disadvantaged dying? Drugs Aging 2010;27(6):435-49.

28. British National Formulary.Volume 60. London: BMJ Group and Pharmaceutical Press: 2010.

29. Reisberg B. Functional Assessment Staging (FAST). Psychopharmacol Bull 1988;24:6539. 
30. Burns A, Lawlor B, Craig S. Assessment scales in old age psychiatry. $2^{\text {nd }}$ ed. London; Martin Dunitz Ltd; 2004.

31. Powell C. The Delphi technique: myths and realities. J Adv Nurs 2003;41(4),376-82.

32. Charlson ME, Pompei P, Ales KL, et al. A new method of classifying prognostic comorbidity in longitudinal studies: development and validation. J Chron Dis 1987;40(5):37383.

33. Pearson Education. SIB-S Manual. Oxford: Pearson Assessment; 2008.

34. Cummings JL, Mega M, Gray K, et al. The Neuropsychiatric Inventory: comprehensive assessment of psychopathology in dementia. Neurology 1994;44:2308-14.

35. Lange RT, Hopp GA, Kang N. Psychometric properties and factor structure of the Neuropsychiatric Inventory Nursing Home version in an elderly neuropsychiatric population. Int J Geriatr Psychiatry 2004;19(5):440-8.

36. Weiner MF, Martin-Cook K, Svetlik DA, et al. The quality of life in late-stage dementia (QUALID) scale. J Am Med Dir Assoc 2000;1(3):114-6.

37. Kiely DK, Volicer L, Teno J, et al. The validity and reliability of scales for the evaluation of end-of-life care in advanced dementia. Alzheimer Dis Assoc Disord 2006;20(3):176-81.

38. Volicer L, Hurley AC, Blasi ZV. Scales for evaluation of end-of-life care in dementia. Alzheimer Dis Assoc Disord 2001;15(4):194-200.

39. Listone HA, Turoff M. The Delphi Method: Techniques and Applications. Reading, MA: Addison-Wesley Publishing Company; 1975.

40. Campbell SM, Cantrill JA. Consensus methods in prescribing research. J Clin Pharm Ther 2001;26:5-14. 
41. Parsons C, McCorry N, Murphy K, et al. Assessment of factors that influence physician decision making regarding medication use in patients with dementia at the end of life. Int $\mathbf{J}$ Geriatr Psychiatry 2014; 29(3):281-90.

42. Brown MA, Sampson EL, Jones L, et al. Prognostic indicators of 6-month mortality in elderly people with advanced dementia: a systematic review. Palliat Med 2013;7(5):389-400.

43. Vetrano DL, Tosato M, Colloca G, et al. Polypharmacy in nursing home residents with severe cognitive impairment: results from the SHELTER study. Alzheimers Dement 2013;9:587-93.

44. Butler DB, Kowall NW, Lawler E, et al. Underuse of diagnostic codes for specific dementias in the Veterans Affairs New England healthcare system. J Am Geriatr Soc 2012;60; $910-5$.

45. Maddison AR, Fisher J, Johnston G Preventive medication use among persons with limited life expectancy. Prog Palliat Care 2011;19:15-21.

46. Garfinkel D, Zur-Gil S, Ben-Israel J. The war against polypharmacy. A new, cost effective geriatric - palliative approach for improving drug therapy in disabled elderly people. Israel Med Assoc J 2007;9:430-4.

47. Garfinkel D, Mangin D. Feasibility study of a new systematic approach for discontinuation of multiple medications in older adults: addressing polypharmacy. Arch Intern Med 2010;170:1648 -54. 
Table 1. Information collected at baseline and every three months thereafter for up to nine months or until death

\begin{tabular}{|c|c|c|c|}
\hline Data collected & Instrument & Source & When \\
\hline Demographic data & & Medical records & Baseline \\
\hline $\begin{array}{l}\text { Type of dementia (if } \\
\text { available) }\end{array}$ & & Medical records & Baseline \\
\hline $\begin{array}{l}\text { Duration of dementia } \\
\text { and age at diagnosis }\end{array}$ & & Medical records & Baseline \\
\hline $\begin{array}{l}\text { Co-morbid medical } \\
\text { conditions in } \\
\text { previous } 3 \text { months }\end{array}$ & $\begin{array}{l}\text { Charlson Co- } \\
\text { Morbidity Index [32] }\end{array}$ & Medical records & Baseline, quarterly \\
\hline $\begin{array}{l}\text { Medications } \\
\text { prescribed in } \\
\text { previous } 3 \text { months }\end{array}$ & & Medical records & $\begin{array}{l}\text { Baseline, quarterly, } \\
\text { death }\end{array}$ \\
\hline \multirow[t]{2}{*}{ Cognitive status } & FAST $^{\mathrm{a}}$ & Named nurse & Baseline, quarterly \\
\hline & $\mathrm{SIB}^{-\mathrm{S}^{\mathrm{b}}}$ & Resident & Baseline, quarterly \\
\hline Behavioural status & NPI-NH ${ }^{c}$ & Named nurse & Baseline, quarterly \\
\hline Quality of life & QUALID $^{\mathrm{d}}$ & Named nurse & Baseline, quarterly \\
\hline \multirow[t]{2}{*}{ Comfort } & SM-EOLD & Named nurse & Baseline, quarterly \\
\hline & CAD-EOLD $^{\mathrm{f}}$ & Named nurse & $\begin{array}{l}\text { Within } 14 \text { days of } \\
\text { death }\end{array}$ \\
\hline Cause of death & & Medical records & $\begin{array}{l}\text { Within } 14 \text { days of } \\
\text { death }\end{array}$ \\
\hline
\end{tabular}

${ }^{\mathrm{b}}$ Severe Impairment Battery - Short Version (SIB-S) [33]: This scale comprises 26 scale items in nine cognitive domains (social interaction, memory, orientation, language, attention, praxis, visuospatial abilities, constructional abilities, and orientation to name) Scores range fom 0 to 50 .

${ }^{c}$ Neuropsychiatric Inventory - Nursing Home version (NPI-NH) [34, 35]. This scale assesses frequency and severity of 12 neuropsychiatric symptoms: delusions, hallucinations, agitation, depression, anxiety, euphoria, apathy, disinhibition, irritability, aberrant motor behaviour, nighttime disturbances and appetite/eating change. The total score ranges from 0 to 144. The caregiver distress score is not included in the total NPI score. It is generated by summing the occupational disruptiveness scores for each of the behavioral domains, with total scores ranging from 0 to 50 .

${ }^{\mathrm{d}}$ Quality of life in late stage dementia (QUALID) scale; an 11-item scale with a total score ranging from 11 to 55 . Lower scores indicate higher quality of life. [36]

${ }^{\mathrm{e}}$ Symptom Management at the End of Life in Dementia (SM-EOLD) [37]. This scale quantifies the frequency with which a resident has experienced nine symptoms in the previous three months; pain, shortness of breath, depression, fear, anxiety, agitation, calm, skin breakdown, and resistance to care. The score ranges fom 0 to 45 , with higher scores indicating better symptom control.

${ }^{\mathrm{f}}$ Comfort Assessment in Dying with Dementia (CAD-EOLD) [38]: this scale assesses 14 symptoms and conditions during the last seven days of life (discomfort, pain, restlessness, shortness of breath, choking, gurgling, difficulty in swallowing, fear, anxiety, crying, moaning, serenity, peace, and calm). 
Table 2. Medication appropriateness ratings for nursing home residents with advanced dementia as determined by the Delphi consensus panel survey

\begin{tabular}{|c|c|c|c|c|}
\hline Always appropriate & Sometimes appropriate & Rarely appropriate & Never appropriate & No consensus reached \\
\hline $\begin{array}{l}\text { Antiemetics } \\
\text { Inhaled bronchodilators } \\
\text { Non-opioid analgesics } \\
\text { Opioid analgesics } \\
\text { Lubricating eye drops } \\
\text { Pressure ulcer products } \\
\text { Local anaesthetics } \\
\text { Emollients } \\
\text { Barrier preparations }\end{array}$ & $\begin{array}{l}\text { Antidiarrhoeals } \\
\text { Laxatives } \\
\text { Antacids } \\
\text { Proton pump inhibitors } \\
\text { Histamine-2 receptor } \\
\text { antagonists } \\
\text { Antispasmodics and other } \\
\text { drugs altering gut motility } \\
\text { Diuretics } \\
\text { Beta-adrenoreceptor } \\
\text { blocking drugs } \\
\text { Nitrates } \\
\text { Antihistamines } \\
\text { Mucolytics } \\
\text { Decongestants } \\
\text { Cough guppressants } \\
\text { Hypnotics } \\
\text { Anxiolytics } \\
\text { Antipsychotic drugs } \\
\text { Other antidepressants } \\
\text { Antiepileptic drugs } \\
\text { N-methyl-D-aspartate } \\
\text { receptor antagonists } \\
\text { Antibacterial drugs } \\
\text { Antifungal drugs } \\
\text { Oral antidiabetic drugs } \\
\text { Thyroid hormones } \\
\text { Antithyroid drugs }\end{array}$ & $\begin{array}{l}\text { Anti-arrhythmic drugs } \\
\text { Alpha-adrenoreceptor } \\
\text { blocking drugs } \\
\text { Acetylcholinesterase } \\
\text { inhibitors } \\
\text { Mineralocorticoid therapy } \\
\text { Glucocorticoid therapy } \\
\text { Calcitonin and parathyroid } \\
\text { hormone } \\
\text { Tamsulosin } \\
\text { Colchicine } \\
\text { Muscle relaxants } \\
\text { Parenteral intravenous } \\
\text { fluids } \\
\text { Dopaminergic drugs used } \\
\text { in Parkinson's disease }\end{array}$ & $\begin{array}{l}\text { Cytotoxic chemotherapy } \\
\text { Lipid-regulating drugs } \\
\text { Central nervous system } \\
\text { stimulants } \\
\text { Immunomodulating drugs } \\
\text { Intravenous nutrition } \\
\text { Disease modifying } \\
\text { antirheumatic drugs } \\
\text { Red blood cell colony } \\
\text { stimulating factor } \\
\text { Angiotensin-converting } \\
\text { enzyme inhibitors and } \\
\text { angiotensin receptor } \\
\text { antagonists } \\
\text { Calcium-channel blockers } \\
\text { Centrally acting } \\
\text { antihypertensive drugs } \\
\text { Vasodilator } \\
\text { antihypertensive drugs } \\
\text { Oral anticoagulants } \\
\text { Parenteral anticoagulants } \\
\text { Antiplatelet drugs } \\
\text { (excluding aspirin) } \\
\text { Aspirin } \\
\text { Cromoglicate and related } \\
\text { therapy } \\
\text { Leukotriene receptor- } \\
\text { antagonists } \\
\text { Expectorants }\end{array}$ & $\begin{array}{l}\text { Cardiac glycosides } \\
\text { Inhaled corticosteroids } \\
\text { Antimuscarinic drugs used } \\
\text { in Parkinsonism } \\
\text { Drugs for management of } \\
\text { chronic bowel disorders } \\
\text { Antiviral drugs } \\
\text { Antiprotozoal drugs and } \\
\text { anthelmintics } \\
\text { Insulins } \\
\text { Other drugs for urinary } \\
\text { retention } \\
\text { Electrolytes } \\
\text { Subcutaneous fluids } \\
\text { Allopurinol }\end{array}$ \\
\hline
\end{tabular}




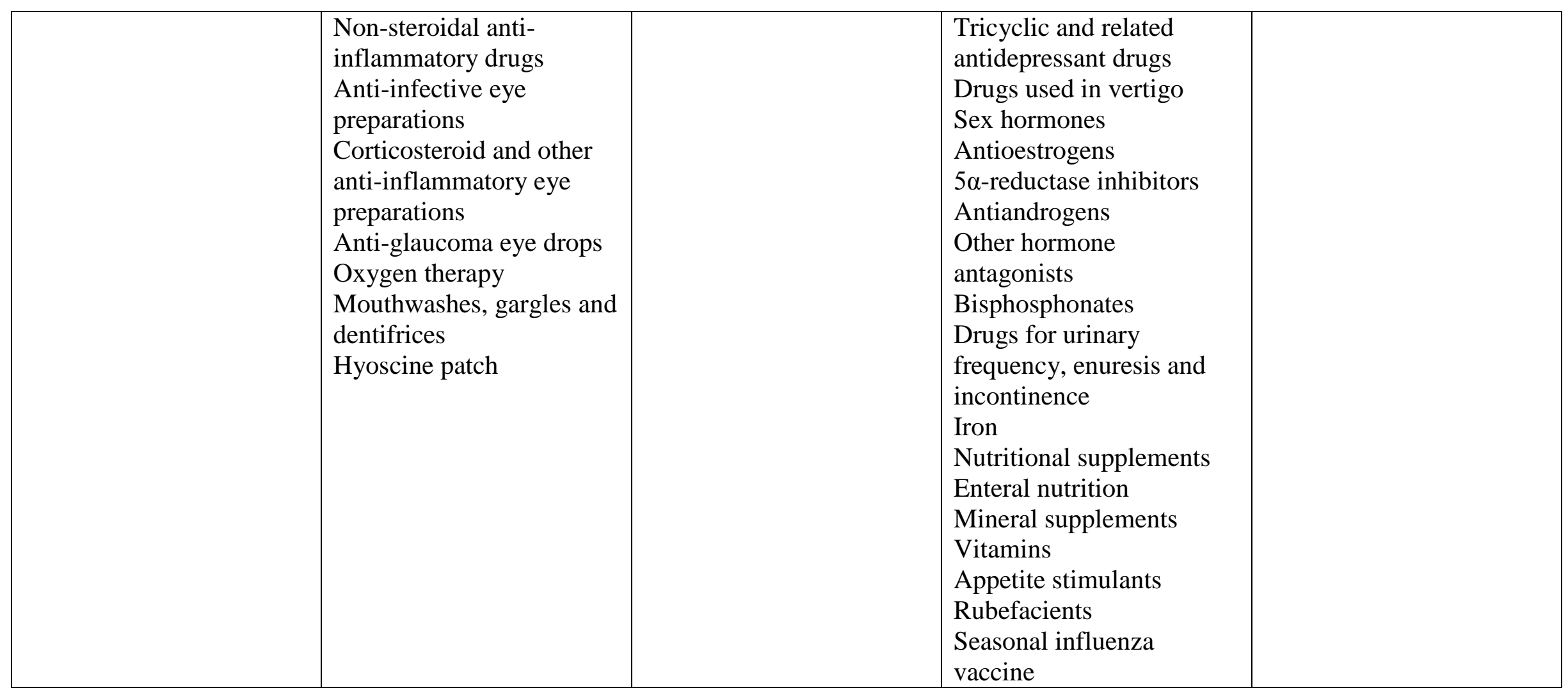


Table $3 \quad$ Nursing home demographics

\begin{tabular}{|lllllllll|}
\hline NH & $\begin{array}{l}\text { Major } \\
\text { provider }^{\text {a }}\end{array}$ & $\begin{array}{l}\text { NH } \\
\text { category }\end{array}$ & $\begin{array}{l}\text { Specialised } \\
\text { dementia } \\
\text { care } \\
\text { provided }\end{array}$ & $\begin{array}{l}\text { No. } \\
\text { of } \\
\text { beds }\end{array}$ & & $\begin{array}{l}\text { Location } \\
\text { sP of } \\
\text { surgeries }\end{array}$ & $\begin{array}{l}\text { No of } \\
\text { GPs }\end{array}$ & $\begin{array}{l}\text { Involvement } \\
\text { of old age } \\
\text { psychiatry } \\
\text { team }\end{array}$ \\
\hline 1 & Yes & Private & No & 40 & City & 8 & 14 & Yes \\
\hline 2 & No & Private & $\begin{array}{l}\text { Yes } \\
(9 \text { beds })\end{array}$ & 49 & $\begin{array}{l}\text { Village/ } \\
\text { rural }\end{array}$ & 10 & 20 & Yes \\
\hline 3 & No & Private & No & 56 & Town & 4 & 21 & Yes \\
\hline
\end{tabular}

${ }^{a}$ Operator of three or more homes or a publicly listed company

$\mathrm{NH}=$ nursing home; $\mathrm{GP}=$ general practice; GPs=general practitioners 
Table 4 Resident data obtained from interview with the resident's named nurse and cognitive assessment at baseline (BL), three (3), six (6) and nine (9) months

\begin{tabular}{|c|c|c|c|c|c|c|c|c|c|c|c|c|c|c|c|c|c|c|c|c|c|c|c|c|}
\hline \multirow[b]{2}{*}{$\begin{array}{l}\text { Resident } \\
\text { number }\end{array}$} & \multicolumn{4}{|c|}{$\begin{array}{l}\text { Cognitive status measured } \\
\text { by FAST } \\
\text { Scores range from } 6 \mathrm{E} \text { to } 7 \mathrm{~F}\end{array}$} & \multicolumn{8}{|c|}{$\begin{array}{l}\text { Behavioural status measured by NPI-NH } \\
\text { Based on } 10 \text { domains. } \\
\text { Scores range from } 12 \text { to } 200\end{array}$} & \multicolumn{4}{|c|}{$\begin{array}{l}\text { Quality of life measured } \\
\text { by QUALID } \\
\text { Scores range from } 11 \text { to } \\
55\end{array}$} & \multicolumn{4}{|c|}{$\begin{array}{l}\text { Comfort measured by } \\
\text { SM-EOLD }^{\mathrm{d}} \\
\text { Scores range from } 0 \text { to } \\
45\end{array}$} & \multicolumn{4}{|c|}{$\begin{array}{l}\text { Cognitive status } \\
\text { measured by SIB-S } \\
\text { Scores range from } 0 \text { to } \\
50\end{array}$} \\
\hline & BL & $3 m$ & $6 \mathrm{~m}$ & $9 m$ & BL & $D^{f}$ & $3 m$ & $D^{f}$ & $6 \mathrm{~m}$ & $D^{f}$ & $9 m$ & $D^{f}$ & BL & $3 m$ & $6 m$ & $9 \mathrm{~m}$ & BL & $3 m$ & $6 \mathrm{~m}$ & $9 m$ & BL & $3 m$ & $6 \mathrm{~m}$ & $9 \mathrm{~m}$ \\
\hline R1.NH1 & $6 e$ & $6 e$ & $6 e$ & $7 \mathrm{a}$ & 15 & 6 & 15 & 2 & 12 & 4 & 24 & 1 & 30 & 23 & 29 & 25 & 29 & 30 & 27 & 36 & & & & \\
\hline R2.NH1 & $7 \mathrm{a}$ & $7 \mathrm{a}$ & $7 \mathrm{a}$ & $7 \mathrm{a}$ & 4 & 3 & 8 & 6 & 7 & 3 & 9 & 4 & 13 & 20 & 20 & 20 & 24 & 30 & 33 & 29 & 8 & & & \\
\hline R3.NH1 & $6 e$ & & & & 31 & 12 & & & & & & & 26 & & & & 21 & & & & 23 & & & \\
\hline R4.NH1 & $7 d$ & $7 d$ & $7 d$ & $7 d$ & 10 & 4 & 18 & 4 & 16 & 6 & 29 & 0 & 22 & 24 & 33 & 29 & 33 & 30 & 31 & 31 & & & & \\
\hline R5.NH1 & $7 f$ & & & & 28 & 6 & & & & & & & 35 & & & & 10 & & & & & & & \\
\hline R6.NH2 & $7 \mathrm{a}$ & $7 \mathrm{a}$ & $7 \mathrm{a}$ & $7 \mathrm{a}$ & 9 & 2 & 16 & 4 & 16 & 2 & 20 & 1 & 13 & 16 & 15 & 15 & 36 & 36 & 40 & 40 & 24 & 16 & 11 & 10 \\
\hline R7.NH2 & $6 e$ & $6 e$ & $6 e$ & $6 \mathrm{e}$ & 18 & 7 & 19 & 6 & 8 & 0 & 8 & 2 & 14 & 15 & 15 & 14 & 23 & 24 & 28 & 32 & 31 & 35 & 35 & 25 \\
\hline R8.NH2 & $7 \mathrm{a}$ & $7 a$ & $7 a$ & $7 \mathrm{a}$ & 36 & 8 & 44 & 9 & 28 & 6 & 32 & 5 & 38 & 39 & 26 & 30 & 22 & 16 & 15 & 29 & 11 & & & \\
\hline R9.NH2 & $6 \mathrm{e}$ & $6 e$ & $6 e$ & $6 e$ & 12 & 5 & 16 & 5 & 21 & 6 & 26 & 4 & 11 & 15 & 13 & 21 & 31 & 25 & 24 & 31 & 43 & 31 & 27 & 12 \\
\hline R10.NH2 & $7 \mathrm{~d}$ & $7 d$ & $7 d$ & $7 \mathrm{~d}$ & 12 & 2 & 12 & 2 & 12 & 1 & 12 & 1 & 18 & 21 & 23 & 26 & 38 & 40 & 40 & 38 & & & & \\
\hline R11.NH3 & $7 \mathrm{a}$ & $7 \mathrm{a}$ & $7 \mathrm{a}$ & $7 \mathrm{a}$ & $10^{\mathrm{g}}$ & 5 & 4 & 1 & 4 & 1 & 10 & 2 & 18 & 15 & 22 & 23 & 34 & 40 & 40 & 34 & 24 & 22 & 13 & 8 \\
\hline R12.NH3 & $7 \mathrm{a}$ & $7 \mathrm{a}$ & & & $32^{\mathrm{g}}$ & 8 & 14 & 4 & & & & & 31 & 19 & & & 30 & 27 & & & 45 & 42 & & \\
\hline R13.NH3 & $7 \mathrm{a}$ & $7 \mathrm{a}$ & $7 \mathrm{a}$ & $7 \mathrm{a}$ & $1^{\mathrm{g}}$ & 1 & 3 & 2 & 8 & 3 & 18 & 1 & 12 & 21 & 18 & 30 & 30 & 21 & 15 & 21 & 40 & 24 & 33 & 34 \\
\hline R14.NH3 & $7 b$ & $7 b$ & $7 \mathrm{~b}$ & & $28^{\mathrm{g}}$ & 9 & 24 & 9 & 56 & 18 & & & 31 & 24 & 25 & & 29 & 35 & 22 & & & & & \\
\hline R15.NH3 & $7 \mathrm{c}$ & & & & $41^{g}$ & 9 & & & & & & & 48 & & & & 28 & & & & & & & \\
\hline
\end{tabular}


$\mathrm{R}=$ Resident

$\mathrm{H}=$ Nursing Home

${ }^{\mathrm{a}}$ Functional Assessment Staging. Ranges from FAST 6E to FAST 7F for recruited residents

bNPI-NH: Neuropsychiatric Inventory - Nursing Home. Total score ranges from 12 to 120 for the 10 domains summed, with lower scores indicating fewer behavioural symptoms

'QUALID: Quality of Life in Dementia Scale. Total score ranges from 11 to 55, with lower scores indicating higher quality of life

dSM-EOLD: Symptom Management at the End of Life in Dementia. Score ranges from 0 to 45, with higher scores indicating better symptom control

${ }^{\mathrm{e}} \mathrm{SIB}-\mathrm{S}$ : Severe Impairment Battery - Short Version. Score ranges from 0 to 50, with lower scores indicating greater impairment

${ }^{\mathrm{f}} \mathrm{D}$ : Caregiver distress score. Total score ranges from 0 to 50 , with lower scores indicating less occupational disruptiveness

${ }^{\mathrm{g}}$ Change of nurse completing NPI-NH at 3,6 and 9 months

\section{Resident died}

No longer resident in nursing home

Resident refused/unable to complete 
Table 5 Number of medications in each appropriateness category and number of residents taking medications in these categories at each data collection timepoint

\begin{tabular}{|c|c|c|}
\hline $\begin{array}{l}\text { Appropriateness category/data } \\
\text { collection point }\end{array}$ & Medications prescribed, n (\%) & $\begin{array}{l}\text { Residents taking medications } \\
\text { in each category, } \mathrm{n}(\%)\end{array}$ \\
\hline $\begin{array}{l}\text { Baseline } \\
\text { Never appropriate } \\
\text { Rarely appropriate } \\
\text { Sometimes appropriate } \\
\text { Always appropriate } \\
\text { No consensus } \\
\text { Not classified } \\
\text { Overall }\end{array}$ & $\begin{aligned} 61 & (25.7) \\
5 & (2.1) \\
89 & (37.6) \\
40 & (16.9) \\
5 & (2.1) \\
37 & (15.6) \\
237 & (100.0)\end{aligned}$ & $\begin{array}{c}14(93.3) \\
5(33.3) \\
15(100.0) \\
15(100.0) \\
5(33.3) \\
13(86.7) \\
15(100.0)\end{array}$ \\
\hline $\begin{array}{l}3 \text { months } \\
\text { Never appropriate } \\
\text { Rarely appropriate } \\
\text { Sometimes appropriate } \\
\text { Always appropriate } \\
\text { No consensus } \\
\text { Not classified } \\
\text { Overall }\end{array}$ & $\begin{array}{c}53(23.6) \\
10(4.4) \\
95(42.2) \\
34(15.1) \\
2(0.9) \\
31(13.8) \\
225(100.0)\end{array}$ & $\begin{array}{c}12(100.0) \\
7(58.3) \\
12(100.0) \\
12(100.0) \\
2(16.7) \\
11(73.3) \\
12(100.0)\end{array}$ \\
\hline $\begin{array}{l}6 \text { months } \\
\text { Never appropriate } \\
\text { Rarely appropriate } \\
\text { Sometimes appropriate } \\
\text { Always appropriate } \\
\text { No consensus } \\
\text { Not classified } \\
\text { Overall }\end{array}$ & $\begin{aligned} 43 & (22.9) \\
7 & (3.7) \\
74 & (39.4) \\
34 & (18.1) \\
5 & (2.7) \\
25 & (13.3) \\
188 & (100.0)\end{aligned}$ & $\begin{array}{c}11(100.0) \\
4(36.4) \\
11(100.0) \\
11(100.0) \\
5(45.5) \\
10(90.9) \\
11(100.0)\end{array}$ \\
\hline $\begin{array}{l}9 \text { months } \\
\text { Never appropriate } \\
\text { Rarely appropriate } \\
\text { Sometimes appropriate } \\
\text { Always appropriate } \\
\text { No consensus } \\
\text { Not classified } \\
\text { Overall }\end{array}$ & $\begin{aligned} 39 & (24.7) \\
5 & (3.2) \\
64 & (40.5) \\
29 & (18.4) \\
2 & (1.3) \\
19 & (12.0) \\
158 & (100.0)\end{aligned}$ & $\begin{array}{c}10(100.0) \\
4(40.0) \\
10(100.0) \\
10(100.0) \\
2(20.0) \\
8(80.0) \\
10(100.0)\end{array}$ \\
\hline $\begin{array}{l}\text { Post-death } \\
\text { Never appropriate } \\
\text { Rarely appropriate } \\
\text { Sometimes appropriate } \\
\text { Always appropriate } \\
\text { No consensus } \\
\text { Not classified } \\
\text { Overall }\end{array}$ & $\begin{array}{c}3(12.0) \\
1(4.0) \\
11(44.0) \\
7(28.0) \\
0(0.0) \\
3(12.0) \\
25(100.0)\end{array}$ & $\begin{array}{c}1(25.0) \\
1(25.0) \\
3(75.0) \\
4(100.0) \\
0(0.0) \\
1(25.0) \\
4(100.0)\end{array}$ \\
\hline
\end{tabular}

